\title{
IMAGENS INSENSATAS INFANTIS
}

\section{INSENSATE CHILDISH IMAGES}

\section{Camila Cilene Zanfelice}

Uma câmera filmadora em uma escola de educação infantil, deslizando por entre as mãos de algumas crianças, produzindo imagens durante períodos e espaços de brincar, na realização de uma pesquisa de mestrado ${ }^{1}$, cujo procedimento metodológico consistiu na entrega de uma câmera filmadora às crianças, solicitando que elas próprias filmassem suas brincadeiras, com o objetivo de produzir uma experiência de pesquisa específica de produção de imagens com crianças, e experimentar formas de pensar as crianças, o brincar, e a infância, com as imagens produzidas. Possibilidade de inventar linhas de fuga latejantes no pensamento, e nas invenções, com movimentos de esquecimento, esvaziamento e transbordamento, desorganização, desfiguração. Potências que afetam e modificam (ou não). Uma aposta.

Inserir no texto imagens insensatas². Instaurar sentidos indomáveis, incoerentes, inaceitáveis, inaparentes. Inventar.

Deixar-se contagiar por outra lógica de “espiar”: o mundo pelas bordas, pelo limite, que escapa, expande, extrapola. Aproximação por choque. Duvidar, sem pretender constatar.

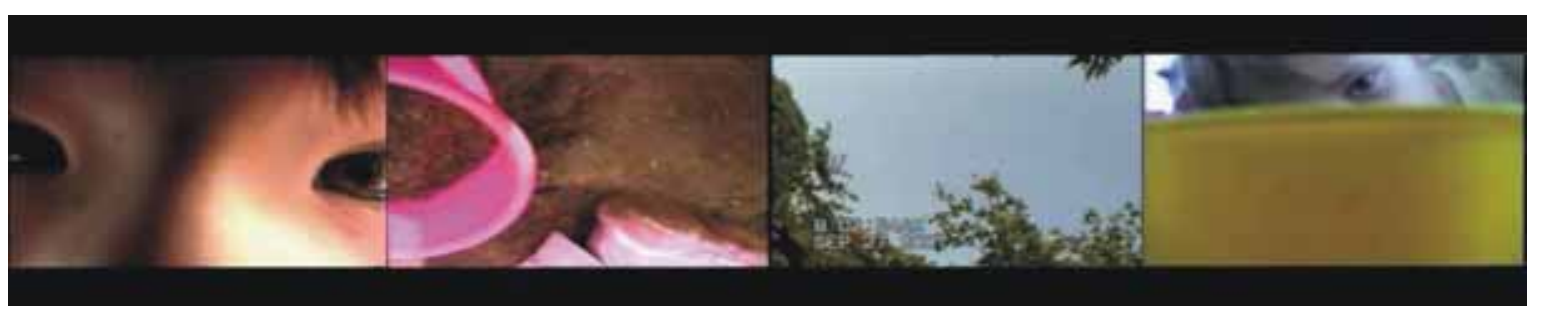

Nas imagens, tudo margens. Cortes, rupturas. Belezas, intensidades, impacto de meias-imagens. O mundo. Simples e complexamente ${ }^{3}$. Inaparente.

\footnotetext{
1 Pesquisa em andamento, financiada pela FAPESP.

2 As imagens apresentadas neste artigo foram retiradas de algumas vídeo gravações feitas pelas crianças.

3 Comentário de Elenise Cristina Pires de Andrade, a quem agradeço pelas conversas e indicações.
} 
Ao acaso, como nas intempestivas presenças de luzes e cores - intempestiva escura sombra que se faz com um concentrado de cores por entre luzes. Corpos sombras de passagem. Sombras, passagem de corpos cartografados. Outros corpos presentes por entre as luzes e as cores. Funcionamento do corpo esvaziado pela sombra.

Funcionamento esvaziado, sombra transbordante. Imagens que se produzem ao acaso.

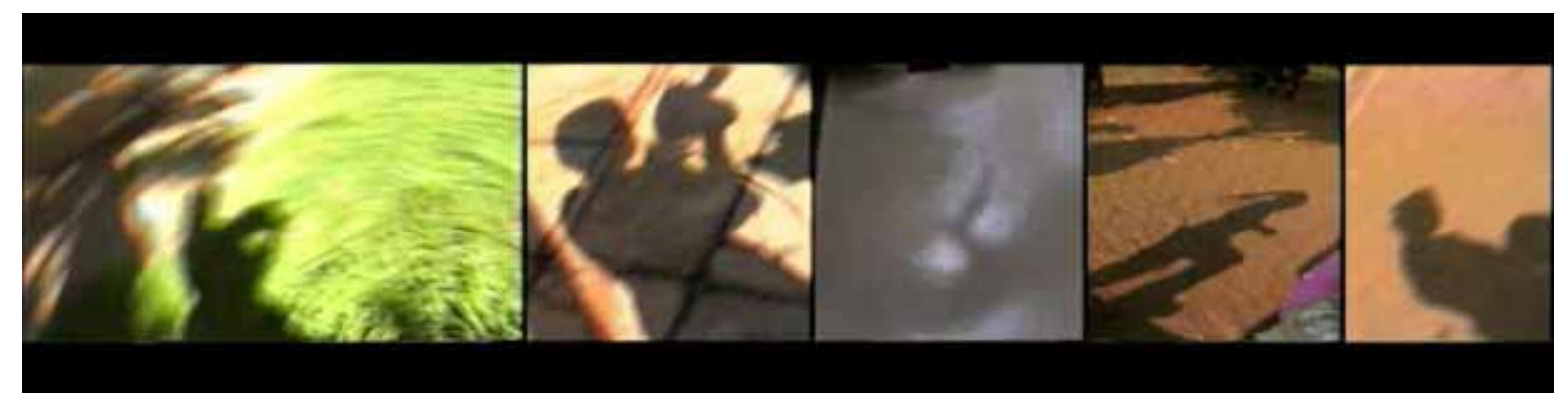

Como não bastasse a novidade de uma câmera, na escola, em poder das crianças, o

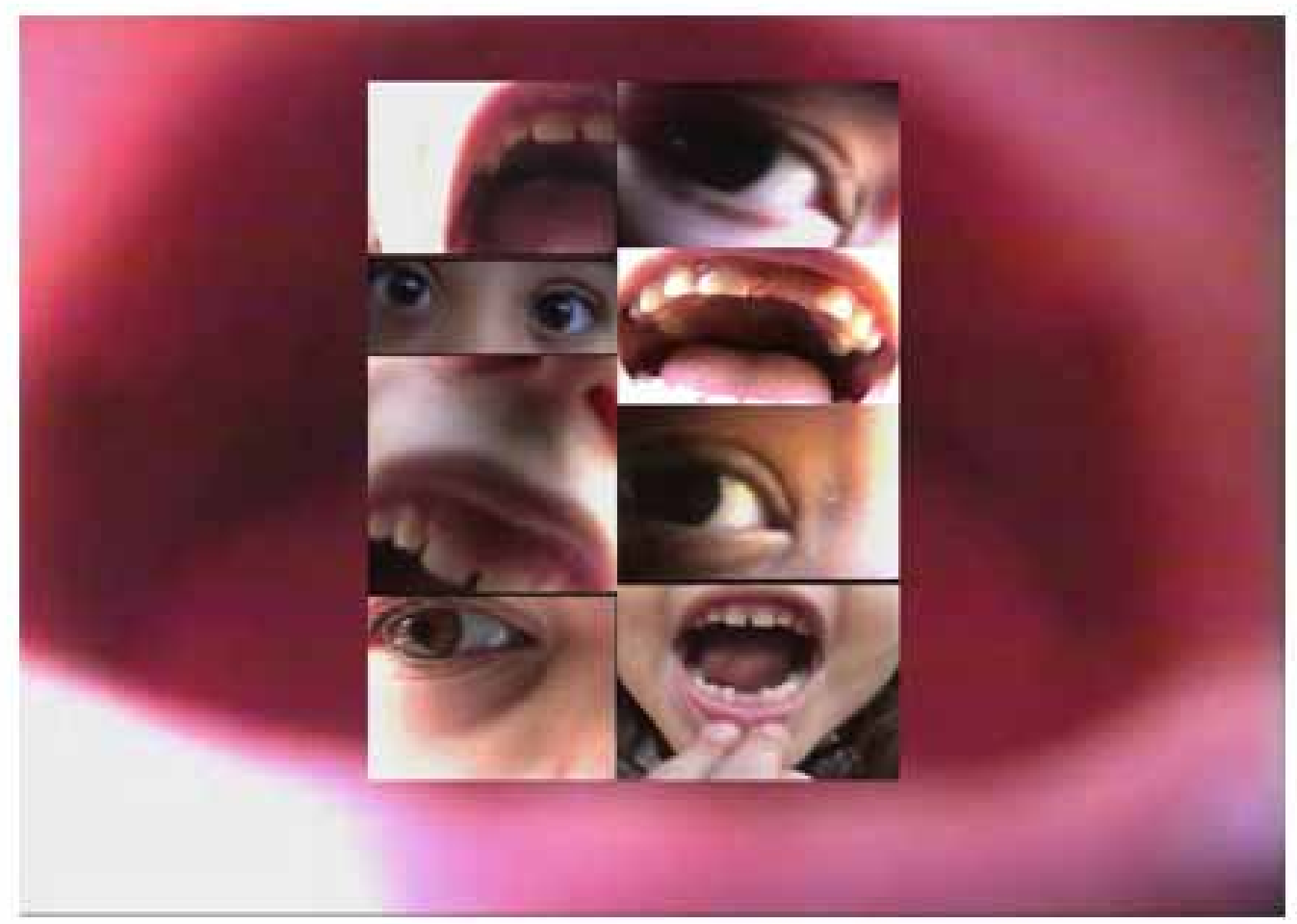

acaso, e as margens, outros movimentos peculiares surpreenderam, roubaram a atenção, pois colocavam em cena: bocas, olhos, dentes, línguas, ar quente, saliva. Em alguns momentos, sem hesitação, a câmera filmadora era agarrada e trazida para perto dos olhos, indo ao encontro de outros corpos, bocas e olhos. Quase dentro das bocas, grudada aos olhos frente à 
lente, a câmera entrava em curiosa composição. Movimento intrigante, pelo qual a câmera se ligava aos corpos, aos sentidos, e estes, à câmera.

Nestas ligações inusitadas, uma loucura de afectos: umidade dos olhos, brilho da boca. Incoerências, esquecimentos do funcionamento dos órgãos, dos sentidos, latejam pelas imagens. Olhos engolindo, bocas olhando. Sensações que esvaziam os "olhos de ver", as "bocas de engolir", e expressam a incapacidade de dizer um sentido último (WUNDER, 2008), de fazer funcionar um sentido. Imagens insensatas, non sens, que impossibilitam fixar um único sentido, pois procedem por esvaziamento, o que transborda possibilidades para criações inúmeras.

O sentido não é algo a ser descoberto, mas algo a produzir, e é sempre em função do não-senso que ele é possível, que podemos produzir sentidos (DELEUZE, 1974, p. 74). As imagens não contém nada (nenhum sentido) a ser descoberto, revelado, mas são possibilidades para a produção de algo novo. Não se trata de produzir, inventar sentidos para as imagens, mas de produzir sentidos com elas, para além, criando, movimentando pensamentos.

Imagens que afetam, pela sua insensatez, e fazem produzir sentidos pelas relações com o mundo; sensações, para além dos processos de percepção, compreensão, ou ainda, representação de uma dada realidade. As imagens que não representam, fazem pensar. Saem da figuração, representação, narração, e entram em relação com a ordem de sensações (DELEUZE, 2007). A sensação que se produz está além do “ver” e do “sentir”, ela

\footnotetext{
é um algo mais que captamos para além da percepção (pois essa só alcança o visível) e o captamos porque somos por ele tocados, um algo mais que nos afeta para além dos sentimentos (pois esses só dizem respeito ao eu). "Sensação" é precisamente isso que se engendra em nossa relação com o mundo para além da percepção e do sentimento (ROLNIK, 2002, p. 2 e 3).
}

Imagens que saboreiam, afetam, nos encontros, envolvem, engendram. "Pintamos, esculpimos, compomos, escrevemos com sensações. Pintamos, esculpimos, compomos, escrevemos sensações” (DELEUZE; GUATTARI, 1992, p. 216). Essa possibilidade de produção de sensações e afectos pelo texto, pelas imagens, permite ultrapassar limites (da escrita, do entendimento, dos sujeitos que vêem, sentem, lêem, escrevem...). 
Encontrar espaços para pensar estas possibilidades de encontro com o mundo, de romper limites com a produção das imagens pelas crianças; circular entre conceitos apresentados por Gilles Deleuze, Félix Guattari e autores que também buscam inspiração na Filosofia da Diferença. Apostar que nos encontros com as imagens e alguns conceitos seja possível pensar a educação, as crianças, com suas "experimentações insensatas", com o non sens. Força e poder de experimentar o non sens. Roubar a sua potência. Provocar ressonâncias pelas imagens, produzindo um texto.

Haveria, na relação com estas imagens, insensatas, uma força que leva a um exercício criativo de pensamento, uma vez que "pensar é romper com a passividade, é sofrer a ação de forças externas que o mobilizem" (VASCONCELLOS, 2006, p.5); imagens latejantes, que liberam o pensamento, afetam sem coerência, sem intenção; que fogem das interpretações, do reconhecimento, dos registros pedagógicos que as fixam um sentido.

Nestes registros, as imagens de obviedades levam a identificar, re-conhecer algo anteriormente dado, uma representação (nas composições apresentadas, representação de um corpo organizado com ações e movimentos pré-estabelecidos). Aproximação que leva a paralisar, fixar o pensamento. Ao interpretar a imagem, encerra-se a produção de sentidos; um único sentido já estaria posto a priori; o encontro com as imagens revela sentidos já definidos.

Esse modo (representacional) de pensar que fixa, controla a expressão, ou os sentidos, se aproxima de uma linguagem da representação, que segundo Larrosa (1994), deve apresentar de uma forma repetida, representar, duplicar externamente o que já estava apresentado no interior (subjetividade dos indivíduos).

\section{Este (questionável) movimento de} interiorização resulta em duas proposições: de que existe um sujeito, o criador da imagem, que é portador de interioridade (subjetividade do indivíduo pensada como caixa-arquivo); e de que a própria imagem é portadora de um "dentro", um clichê (DELEUZE, 1990; DELEUZE; GUATTARI, 1992), definido por André Parente (1993) como "imagens que supõem um espaço de interioridade", que contém algo a ser mostrado/descoberto em seu interior. Efeitos de um tipo de programação forjada
Disfarça, tem gente olhando. Uns olham pro alto, cometas, luas, galáxias. Outros olham de banda, lunetas, luares, sintaxes.

De frente ou de lado, sempre tem gente olhando, olhando ou sendo olhado Outros olham pra baixo, procurando algum vestígio do tempo que a gente acha, em busca do espaço perdido. Raros olham para dentro, já que não tem nada. Apenas um peso imenso, a alma, esse conto de fada.

(Paulo Leminski) 
por um novo regime de controle e poder - que destrói as expectativas de que o avanço tecnológico pudesse refletir um nomadismo generalizado, e ao contrário, resulta em uma paralisia geral - que provoca nas pessoas, que já possuem clichês psíquicos, uma inércia em relação ao movimento e à velocidade das imagens que lhes são apresentadas e as impedem de ver as imagens que "vêm de fora” (PARENTE, 1993, p.18).

Fugindo dessa lógica e dos registros, as crianças, criadoras das imagens, ao que parece, não se mostram - pois ao se mostrarem caracterizar-se-ia uma representação de si mas produzem outros possíveis. Não reproduzem sentidos ocultos em seu suposto “eu” interior, mas extravasam para outras formas, outras possibilidades de comporem as suas relações com o mundo, com imagens que se afastam de um estado faltante (no qual representariam coisas ausentes, sendo elas mesmas a falta daquilo que representassem), e passam a um estado de transbordamento, porque permitem ir além, produzem sentidos infinitos, como lugares de criação. Produzem imagens infantis, potências de afetar, como o que não tem representação, ainda não se constituiu organicamente, organizadamente; como ruptura de identidades, de classificações.

Para Amorim (2007), é preciso manter a vontade, a capacidade de deslizar sobre a imagem, e com ela, colocar o pensamento em movimento, estabelecendo uma política de superfície, ou seja, não buscando nela ou por trás dela (DELEUZE, 1995) uma representação, algo dado, mas com ela, sobre ela, através dela, ou ainda, a partir dela, produzir novas formas de pensar, e diferentes sentidos. A aproximação, o encontro com as imagens produzidas pelas crianças - imagens entendidas como potências do pensamento - não ocorre pelo simples reconhecimento ou interpretação de dados. Uma outra forma de aproximação possível, por deslizamento, e que pode ser pensada a partir do não-óbvio cria novas possibilidades para se pensar as relações entre os olhos e as bocas, olhares e sabores.

Nestes encontros com as imagens, fugir da obviedade daquilo que vemos: corpos orgânicos: boca sem dente e bocas abertas povoadas de dentes; olhos olhando.

Ao compor as imagens, surgem rupturas, desfigurações.

Devir dos corpos, bocas e olhos. Devir, aqui, está sendo entendido como fuga, desterritorialização, e aproximação. Um processo. O que se busca num devir é "um 
relançamento da produção desejante ou da experimentação"; “desejar é passar por devires” (ZOURABICHVILI, 2004) ${ }^{4}$.

Potência que arrasta o corpo para um outro elemento, desembaraçando-o de sua inércia e de sua materialidade. Corpos de passagem, corpos desencarnados, corpos dessubjetivados, corpos abertos ao fora inumano desdobrado em eterno e efêmero. Corpo inconsciente, fora da consciência, tomado pelas ondas nervosas da sensação que o toma e nele se amplia. (FONSECA, 2005, p. 107)

Fragmentos dos corpos tornam-se disponíveis, abertos, deixando atravessarem.

Desorganização, ruptura do ser. Corpos de passagem.

Corpos atravessados por uma vitalidade não-orgânica, que é a "relação do corpo com forças ou poderes imperceptíveis que dele se apossam ou dos quais ele se apossa”, no registro das intensidades. Corpo em devir, com poder de afetar e ser afetado, ligado à experimentação (Deleuze, 1997), às intensidades que o povoam, como umidades, o quente, o calor. Não é mais um Eu que sente, age, é “uma bruma brilhante, um vapor amarelo e sombrio" que se compõe de afectos, e experimenta movimentos, velocidades (DELEUZE; GUATTARI, 1996, p. 215).

Olhos e bocas abertos se oferecem, dispostos a contagiar. Olhos de fome do outro. Saborear. Engolir o outro, misturar-se. Órgãos em excesso. Boca que nos engole e que vomita sentidos. Fome transbordante (excesso de desejo); vazamento da subjetividade que permite ligar-se ao outro. Produção de entre - n - subjetivações. Seres em excesso, ocupados pelas máquinas desejantes e o corpo-sem-órgãos (BIRMAN, 2000).

O desejo de engolir, capturar o outro, que se agencia com as imagens apresentadas está mais ligado a um transbordamento, que permite vazar, escorrer e ocupar lugares, ligar-se ao outro, do que a uma suposta falta - o que pressupõe um sujeito faltante - que impulsiona o sujeito a querer preenchê-la. Ao que parece, o desejo é de transbordamento, não de preenchimento; desejo condicionado ao encontro imprevisível que agrega, e não à busca desvairada por completar-se.

4 Para mais, ver: Deleuze e Guattari (1997). 
Desfiguração. Boca que vira olho e nos vê; olhos que nos saboreiam. Outra/nova boca/olho que se abre. Se fecha.

Insensatez transbordante de possíveis.

Por entre intervalos de sombras, incoerências de olhos e bocas. Infância dos corpos e órgãos.

A cada vez

Fugir dos clichês

Inventar Intervalos Incoerentes

Infantis

Insensatas

Inusitadas

Imagens

Incapacidade de dizer Intensidade

Novidade

Deslizar atravessar agregar transbordar afetar contagiar

Passagens
Margens
Meias-imagens

Desfiguração
Olho
Boca
Sombra
Sensação.




\section{REFERÊNCIAS}

AMORIM, A. C. R. Fotografia, som e cinema como afectos e perceptos no conhecimento da escola. Revista Teias, Rio de Janeiro, ano 8, n. 15-16, jan/dez, 2007.

BIRMAN, J. Os signos e seus excessos. A clínica em Deleuze. In: ALLIEZ, E. (Org). Gilles Deleuze: uma vida filosófica. São Paulo: Ed. 34, 2000. (Coleção TRANS).

DELEUZE, G. A imagem-tempo. Cinema 2. São Paulo: Brasiliense, 1990. . Conversações. São Paulo: Editora 34, 1995.

(Estéticas).

Francis Bacon: lógica da sensação. Rio de Janeiro: Jorge Zahar Ed., 2007. . Mil Platôs - capitalismo e esquizofrenia. (vol.3). Rio de Janeiro: Editora 34, 1996.

. Mil Platôs - capitalismo e esquizofrenia. (vol.3). Rio de Janeiro: Editora 34, 1997.

.; GUATTARI, F. O que é a filosofia? São Paulo: Editora 34, 1992.

FONSECA, T. M. G. Imagens que não agüentam mais. Episteme, Porto Alegre, n.20, p. $101-110$, jan./jun. 2005.

LARROSA, J. Tecnologías do eu e educação. In: SILVA, T. T. (Org.). O sujeito da educação: estudos foucaultianos. Petrópolis: Vozes, 1994.

PARENTE, A. (org.) Imagem-máquina: a era das tecnologias do virtual. Rio de Janeiro: Editora 34, 1993.

ROLNIK, S. Subjetividade em obra. Lygia Clark, artista contemporânea. Disponível em: http://www.pucsp.br/nucleodesubjetividade/Textos/SUELY/Subjemobra.pdf. Acesso em: 03 out. 2007.

VASCONCELlOS, J. Deleuze e o cinema. Rio de Janeiro: Editora Ciência Moderna Ltda., 2006.

WUNDER, A. Foto quase grafias: o acontecimento por fotografias de escolas, 2008. $127 \mathrm{fl}$. Tese (Doutorado em Educação) - Faculdade de Educação, Universidade Estadual de Campinas, Campinas, 2008.

ZOURABICHVILI, F. O vocabulário de Deleuze. Tradução de André Telles. Rio de Janeiro: Relume Dumará, 2004. [Digitalização e disponibilização da versão eletrônica: Instituto de Filosofia e Ciências Humanas - Universidade Estadual de Campinas: cienti.ifch@gmail.com] 
Recebido em: 10/03/2008

Publicado em: 20/10/2008 